\title{
Comparison of the Difference of Appearance Satisfaction and Self- Esteem according to Self-Coordination of Nursing College Students
}

\author{
Pil-Hwan Kim ${ }^{1}$ and Kyoung-Nam Kim ${ }^{2}$ \\ ${ }^{1}$ Department of Nursing, Changshin University, Korea \\ ${ }^{2}$ Department of Nursing, Busan Women's College, Korea \\ ${ }^{1}$ feelnrkim@cs.ac.kr, ${ }^{2}$ fairycc@bwc.ac.kr
}

\begin{abstract}
This study is a descriptive research study to investigate the difference between self-esteem and physical satisfaction according to the self-coordination of nursing college students. The participants of this study were 159 students of $C$ university nursing students in $C$ city. The collected data were analyzed using SPSS WIN 20.0 program. The subjects interested in appearance management were skin and make-up 32.7\%, weight, and body management $30.9 \%$, reason for self-satisfaction $85.5 \%$, and information provided through the internet $73.5 \%$ respectively. There was a statistically significant difference in satisfaction of appearance according to self-coordination ( $t=-27.5, p<.001)$. There was a statistically significant difference in self-esteem according to self-coordination $(t=-5.2, p<.001)$. Based on the results of this study, the development and operation of the coaching program for the self - coordination method will contribute to enhancing the physical satisfaction and selfesteem of the subjects.
\end{abstract}

Keywords: Nursing students, Appearance management, Satisfaction, Self-esteem

\section{Introduction}

Appearance management behaviors start from the perception that the innate appearance can be changed and improved through efforts and that managing appearance can give satisfaction to the self and enable people to take precedence in a social and cultural context [1]. People today are increasingly interested in appearance and are investing a lot of time and money in appearance management behaviors to improve their appearance regardless of gender [2]. It is believed that desirable self-coordination behaviors of nurses, most of whom are still women, can increase the job satisfaction of nurses as a profession, improve their image to customers visiting the hospital, and have a positive impact on customers' satisfaction with hospital use. In addition, recently, hospitals are also providing makeup education for nurses according to the characteristics of wards, and the reason for coaching the nurses for facial hue and make-up technique is said that the make-up that suits the psychological and physical condition of patients can give the patients a high level of trust and stability [3]. Therefore, this study investigated various characteristics of nursing college students, such as interest in self-coordination, interest parts, and costs, and compared the

Article history:

Received (January 8, 2019), Review Result (February 8, 2019), Accepted (March 12, 2019) 
difference in appearance satisfaction and self-esteem before and after self-coordination. This study aimed to provide basic data that will make nursing college students have a positive perception of their self-coordination and will contribute to improving their image.

\section{Body}

\subsection{Purpose}

This study aims to investigate the difference in appearance satisfaction and self-esteem before and after self-coordination among nursing college students.

\subsection{Method}

This study is descriptive survey research to investigate the difference in appearance satisfaction and self-esteem before and after the self-coordination of nursing college students.

\subsection{Instruments}

1) Appearance Satisfaction

Lee [4], Han \& Kim [5], and Kang's [6] tools were modified and supplemented to be used as a tool to measure appearance satisfaction. This used a 5-point Likert scale and consisted of 22 items with 14 items on the perception of appearance, 4 items on satisfaction with appearance, and 4 items on self-confidence in appearance. The higher the total score, the higher the satisfaction with the appearance. The reliability of this study was indicated by a Cronbach's $\alpha$ of .89 .

2) Self-esteem

The Rosenberg [7] Self-Esteem Inventory (RSEI) used in Suh's [8] study, which was designed to measure comprehensively individual value, satisfaction, self-esteem, and selfdeprecation, was used to measure self-esteem. This consisted of a total of 10 items with 5 positive items and 5 negative items and used a 4-point Likert scale. The higher the total score, the higher the satisfaction with the appearance. Suh's [8] study had Cronbach's $\alpha$ of .86, and the reliability of this study was indicated by a Cronbach's $\alpha$ of .88 .

\subsection{Data Analysis}

The collected data were analyzed using the SPSS Win 20.0 program. The mean and standard deviation were obtained, and a t-test was conducted to examine the difference in satisfaction with appearance and self-esteem before and after the self-coordination of nursing college students.

\section{Results}

\subsection{General Characteristics of this Study Subjects}

According to the analysis of general characteristics of the subjects, for gender, age, grade, pocket money, appearance management costs, the expenditure on hair style, the parts of interest in appearance management, the reasons for appearance management, and provide information [Table 1]. 
Table 1. General characteristics of subjects $(\mathrm{N}=159)$

\begin{tabular}{|c|c|c|}
\hline Characteristics & Categories & $\mathrm{N}(\%)$ or Mean $\pm \mathrm{SD}$ \\
\hline \multirow{2}{*}{ Gender } & Man & $23(14.5)$ \\
\hline & Woman & $136(85.5)$ \\
\hline \multirow{4}{*}{$\operatorname{Age}(y r)$} & $19-20$ & $128(81.1)$ \\
\hline & $21-22$ & $29(18.4)$ \\
\hline & $\geq 23$ & $2(0.5)$ \\
\hline & & $19.3 \pm 0.3$ \\
\hline \multirow{2}{*}{ Grade } & 1 & $107(67.2)$ \\
\hline & 2 & $52(32.8)$ \\
\hline \multirow{7}{*}{$\begin{array}{l}\text { Money(month) } \\
(10,000 \text { Won })\end{array}$} & $<10$ & $17(10.6)$ \\
\hline & $10-19$ & $17(10.6)$ \\
\hline & $20-29$ & $40(25.1)$ \\
\hline & $30-39$ & $53(33.3)$ \\
\hline & $40-49$ & $17(10.6)$ \\
\hline & $\geq 50$ & $15(9.8)$ \\
\hline & & $34.8 \pm 0.8$ \\
\hline \multirow{4}{*}{$\begin{array}{c}\text { Appearance management } \\
\text { costs } \\
\text { (Month) } \\
(10,000 \text { Won })\end{array}$} & Hairstyle & $1.8 \pm 1.5$ \\
\hline & Skin \& Makeup & $3.5 \pm 3.0$ \\
\hline & Fashion & $8.5 \pm 6.2$ \\
\hline & Body Weight \& Shape & $2.0 \pm 0.7$ \\
\hline \multirow{5}{*}{ Appearance interest } & none at all & $1(0.8)$ \\
\hline & none & $8(5.0)$ \\
\hline & Average & $45(28.3)$ \\
\hline & Yes & $74(46.5)$ \\
\hline & Very interested. & $31(19.4)$ \\
\hline \multirow{4}{*}{ Part of interest } & Hairstyle & $13(8.1)$ \\
\hline & Skin \& Makeup & $52(32.7)$ \\
\hline & Fashion & $45(28.3)$ \\
\hline & Body Weight \& Shape & $49(30.9)$ \\
\hline \multirow{3}{*}{$\begin{array}{l}\text { Reason for appearance } \\
\text { management }\end{array}$} & Self Satisfaction & $136(85.5)$ \\
\hline & Lover & $5(3.1)$ \\
\hline & Awareness around & $18(11.4)$ \\
\hline \multirow{5}{*}{ Provide information } & Internet & $117(73.5)$ \\
\hline & TV, Radio, newspaper & $14(8.8)$ \\
\hline & Friends & $17(10.6)$ \\
\hline & $\begin{array}{c}\text { Company promotional } \\
\text { materials }\end{array}$ & $4(2.5)$ \\
\hline & None & $7(4.6)$ \\
\hline
\end{tabular}




\subsection{The Difference between Appearance Satisfaction and Self-esteem before and after Self-coordination of the Study's Subjects}

The mean of appearance satisfaction before self-coordination of the subjects was $3.3 \pm 0.2$, and the mean of appearance satisfaction after self-coordination was $3.7 \pm 0.2$. These results showed that there was a statistically significant difference $(\mathrm{t}=-27.5, \mathrm{p}<.001)$. The mean of self-esteem before self-coordination was $2.3 \pm 0.2$, and the mean of self-esteem after selfcoordination was $2.5 \pm 0.1$, which showed that there was also a statistically significant difference $(\mathrm{t}=-5.2, \mathrm{p}<.001)$ [Table 2].

Table 2. Comparison of the difference between appearance satisfaction and self-esteem according to self-coordination $(\mathrm{N}=159)$

\begin{tabular}{|c|c|c|c|c|}
\hline Variables & Categories & Mean \pm SD & $\mathrm{t}$ & $\mathrm{p}$ \\
\hline \multirow{2}{*}{ Appearance satisfaction } & Pretest & $3.3 \pm 0.2$ & \multirow{2}{*}{-27.5} & \multirow{2}{*}{$<.001$} \\
\cline { 2 - 3 } & Posttest & $3.7 \pm 0.2$ & & \multirow{2}{*}{-5.2} \\
\hline \multirow{2}{*}{ Self-esteem } & Pretest & $2.3 \pm 0.2$ & $<.001$ \\
\cline { 2 - 3 } & Posttest & $2.5 \pm 0.1$ & & \\
\hline
\end{tabular}

\section{Discussion}

This study aimed to investigate the difference in appearance satisfaction and self-esteem before and after self-coordination among nursing college students. According to the results of this study, the average monthly pocket money was $34.8 \pm 0.8$ thousand won, and among the appearance management costs, the 'expenditure on fashion' of $8.5 \pm 6.2$ thousand won accounted for the largest proportion, followed by 'skin and makeup' of $3.5 \pm 3.0$ thousand won. As for the parts of interest in appearance management, 'skin and makeup' with $32.7 \%$ accounted for the largest proportion.

In this study, the mean of appearance satisfaction before self-coordination of college students was $3.3 \pm 0.2$, and the mean of appearance satisfaction after self-coordination was $3.7 \pm 0.2$, which showed that there was a statistically significant difference. The mean of selfesteem before self-coordination was $2.3 \pm 0.2$, and the mean of self-esteem after selfcoordination was $2.5 \pm 0.1$, which showed that there was also a statistically significant difference. The study by Park [9] also showed that appearance management behaviors of college students partially affected their satisfaction with their appearance and that specifically, their hair care behaviors and skin care behaviors had a positive influence on their appearance satisfaction. The study by Park [9] also showed that appearance management behaviors of college students partially affected their satisfaction with their appearance and that specifically, their hair care behaviors and skin care behaviors had a positive influence on their appearance satisfaction. However, in the study of Park, unlike the results of this study, appearance management behaviors did not influence self-esteem, and it was reported that their appearance management did not positively affect self-esteem formation and that hair care behaviors and skin care behaviors among college students' appearance management behaviors had a positive effect on negative self-esteem. These results contradict those of this study that there is a statistically significant difference in self-esteem before and after selfcoordination. However, unlike Park's study [9], this study did not divide it into positive selfesteem and negative self-esteem and measure them separately, so it is difficult to directly compare these two studies. 
In this study, there was a statistically significant difference in the subjects' appearance satisfaction and self-esteem before and after self-coordination. Based on the results of this study, developing and operating a program to coach self-coordination methods for selfsatisfaction by considering the specific characteristics of self-coordination behaviors of nursing college students, will contribute to improving their appearance satisfaction and selfesteem.

\section{Conclusion}

According to the results of this study, among the appearance management costs of nursing college students, the 'expenditure on fashion' accounted for the largest proportion, and for the parts of interest in appearance management, 'skin and makeup' accounted for the largest proportion. As for the reasons of appearance management, 'self-satisfaction' accounted for the largest proportion, and for the routes that information is provided, most participants said 'Internet'. In addition, there was a statistically significant difference in appearance satisfaction and self-esteem before and after self-coordination. Therefore, the researchers of this paper propose to develop and apply a program to coach self-coordination methods for nursing students.

\section{Acknowledgments}

This work was supported by Changshin University Research Fund of 2018 (NO. Changshin 2018-32).

\section{References}

[1] H. K. Lee, "Effects of sociocultural attitude toward appearance, body image, and self-esteem on appearance management in middle and high school girls," Korea Academy Industrial Cooperation Society, vol.15, no.2, pp.914-922, (2014)

[2] S. Y. Jo and S. M. Hwang, "A study of effects of gap between actual age and self-perceived age in middleage women on their appearance management behavior and self-esteem," Korean Journal of Aesthetic Society, vol.11, no.6, pp.1137-1146, (2013)

[3] M. R. Back, "The make-up behavior and the influential factors of nurses in hospitals of Busan," M.S. thesis, Department of Nursing the Graduate School Kosin University, Busan, pp.1-6, (2006)

[4] M. S. Lee, "The effects of appearance instrumentality on adolescents' body satisfaction and appearance management behaviors," Korean Journal of Human Ecology, vol.22, no.1, pp.75-88, (2013)

[5] H. R. Han and H. S. Kim, "The effect of appearance satisfaction and appearance consciousness on school adoption among the multicultural family adolescents," The Research Institute of Korean Education, vol.28, no.2, pp.61-76, (2010)

[6] N. S. Kang, "The effect of body satisfaction in university students on appearance management behavior and beauty consumption behavior," Korean Journal of Aesthetic Society, vol.9, no.1, pp.63-80, (2011)

[7] M. Rogenberg, "Society and the adolescent self-image," Princeton, NJ: Princeton University Press, (1965)

[8] M. G. Suh, "The development and effectiveness of an emotional speech program," Ph. D. dissertation, Department of Counseling Psychology Graduate School of Dongsin University, Naju, pp.28-40, (2011)

[9] S. A. Park, "The effects of appearance management behavior on appearance satisfaction and self-esteem," M.S. thesis, Department of Education-Majoring in Beauty Honam University, pp.45-55, (2016) 
Comparison of the difference of appearance satisfaction and self-esteem according to self-coordination of nursing college students

\section{Authors}

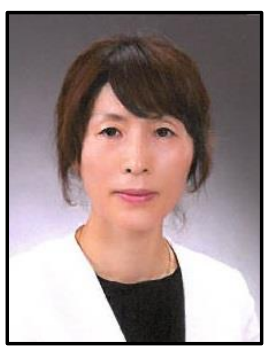

\section{Pil-Hwan Kim}

Department of Nursing, Changshin University

Assistant professor (from 2017)

Acquired doctoral degree in Nursing (2016. 02)

Interests: Complementary and Alternative Nursing Intervention

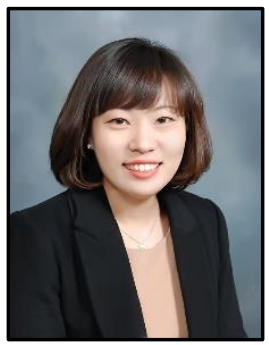

\section{Kyoung-Nam Kim}

Department of Nursing, Busan Women's College

Associate professor (from 2013)

Acquired doctoral degree in Nursing (2012.08)

Interests: Nursing Intervention, Intensive care nursing 